\title{
THE STANDARD STORY OF ACTION AND THE PROBLEM OF AGENTIAL GUIDANCE
}

\author{
Jesús H. Aguilar \\ Rochester Institute of Technology \\ Department of Philosophy \\ aguilar@mail.rit.edu
}

SUMMARY: The problem of agential guidance consists in explaining the possibility of guiding an action in purely reductive causal terms. After examining Harry Frankfurt's articulation of this problem, the standard systemic reductive causal answer is explored and found wanting. Two general explanatory challenges are singled out as decisive in assessing the viability of a causal answer to the problem of agential guidance: first, the correct identification of the actual sources of action guidance in the form of guiding intentions, and, second, the recognition of the limitations of a content-based strategy to identify an action under guidance.

KEY WORDS: systemic agency, guiding intention, causal reduction, agential awareness, sustained causation

RESUMEN: El problema de la agencia guiada consiste en explicar la posibilidad de guiar una acción puramente en términos reduccionistas causales. Después de examinar la articulación que Harry Frankfurt ofrece de este problema, la respuesta causal comúnmente aceptada es explorada y cuestionada. Dos desafíos explicativos generales se identifican como decisivos para evaluar la viabilidad de una respuesta causal al problema de la agencia guiada: primero, el poder identificar correctamente las fuentes detrás de las acciones guiadas a través de intenciones guías, y, segundo, el reconocimiento de los límites de una estrategia basada en el contenido como el modo de identificar una acción que es guiada.

PALABRAS CLAVE: agencia sistémica, intención guía, reducción causal, conciencia agencial, causación sostenida

The prevalent philosophical orthodoxy concerning the nature of agency is a direct consequence of the so called "Standard Story of Action". ${ }^{1}$ According to this story, an action is the causal outcome of a set of non-actional mental items which are the reasons the agent has to act in that particular way. Since agency is typically understood as the capacity to produce an action the standard story of action is also a

${ }^{1}$ This way of identifying the current orthodoxy in action theory apparently started in the early nineties, with D. Velleman (1992) calling it the "Standard Story of Human Action", it has since become a common currency amongst both supporters of this approach to action (Smith 2012) and its critics (Hornsby 2004). 
story about agency. This is a move with significant explanatory consequences. The most significant of these consequences is the claim that once the conditions for the possibility of action are accounted for, the corresponding conditions for agency have also been accounted for. Since accounting for the possibility of action makes use of more basic ingredients, the claim is that these same basic ingredients offer a reductive understanding of agency. The development of the standard story of action during the last decades has been a continuous effort to account for the more nuanced aspects of agency by enriching, expanding, and placing the set of causal antecedents of an action inside a complex agential system. ${ }^{2}$

Most contemporary versions of the standard story embrace the idea that a single type of mental state can account for the whole array of features associated with agency when such a state is conceived as part of an agential system. This type of mental state is usually identified as an intention. Consider, for instance, Alfred Mele's characterization of an intention:

A psychological item (-type), tokens of which initiate and motivationally sustain intentional action, guide and monitor behavior, help coordinate agent's behavior over time and their interaction with other agents, prompt practical reasoning, and appropriately terminate such reasoning. $(1992 \text {, p. 140) })^{3}$

It is hard to imagine a richer set of attributes belonging to any other single type of mental state. Intentions are conceived as performing functions that ordinarily are thought to engage the whole agent, like the capacity to initiate and sustain an action. They are also seen as able to carry out tasks that, given their complexity, are typically associated not with individual mental states but rather with agential faculties like guiding and monitoring behavior across

${ }^{2}$ Some representative examples of this systemic approach to agency can be found in the work of authors like M. Brand (1984), J. Bishop (1989), F. Adams and A. Mele (1989), B. Enc (2003), A. Mele (1992); and, in the sphere of the cognitive sciences, M. Jeannerod (1997, 2006), and E. Pacherie (2000, 2011, 2008).

${ }^{3}$ Mele's list of features associated with an intention is meant to offer the set of features that at least from a commonsensical perspective are typically attributed to this type of mental state. His own analysis of an intention is more nuanced with respect to how all these features come together in a single type of mental state. For example, some of such features are thought to involve separate mechanisms like "perceptual or quasi-perceptual monitors" (1992, p. 223). Nevertheless, this way of talking about intentions as a single type of mental state exhibiting such complex characteristics is widespread amongst defenders of the standard story. 
time and among different agents. Moreover, intentions are thought to be in charge of generating and concluding the process of practical reasoning, which is a defining feature of rational agency.

The fact that the entire functional load associated with agency is carried out by a single type of mental state is the direct consequence of the reductive spirit informing the standard story of action. It is precisely this explanatory reductionism that makes the standard story so compelling for those who support it, and, of course, so problematic for those who reject it. In fact, it is the widespread belief that in general terms this story has been successful that accounts for its status as the contemporary orthodoxy about action and agency. Nonetheless, as befits a predominant orthodoxy the standard story of action has been subjected to constant and varied criticisms since it became the received view. One of these criticisms is the problem of agential guidance which directly relates to the story's reductionist character.

The problem of agential guidance consists in explaining the possibility of guiding an action in purely reductive causal terms when such guidance involves complex functions like the setting of an action's goal, the maintaining of continuous causal influences, and the monitoring of the unfolding action. Its earliest substantial articulation is found in Harry Frankfurt's essay "The Problem of Action" (1978). Here, Frankfurt offers a critical approach to the standard story of action claiming that it fails in providing a viable account of action guidance. However, what makes his criticism stand out is its generality and depth. In Frankfurt's hands, a criticism which could have been circumscribed to the explanatory challenges related to behavioral guidance turns out to be a criticism of the standard story's view about action in general, which explains the title of his essay. The fundamental reason behind the generality of this criticism is that Frankfurt identifies agency itself as a form of guidance: whether a person qualifies as the agent of his bodily movements is equivalent to determining, as he puts it, "whether or not the movements as they occur are under the person's guidance. It is this that determines whether he is performing an action" (1978, p. 72).

Frankfurt's analysis of the place of guidance in agency and his accompanying criticism of the standard story has been essentially neglected. This is particularly striking considering the force of the arguments involved, the potentially very serious consequences for the standard story, and the significant attention given to other aspects of his work on action and agency. One of my main goals here is to 
set the record straight with respect to the significance of Frankfurt's criticism of the standard story of action based on the problem of agential guidance. A second main goal of this essay is to assess whether the standard story under its systemic guise can provide a plausible answer to such criticism.

The first section identifies the main challenges to the standard story of action presented by Frankfurt. In the second section, the most influential answer to these challenges coming from defenders of the standard story in the form of a systemic causalist approach to agency is explored. This discussion leads to a third and final section where some significant problems related to the standard story's systemic approach to agential guidance are identified, suggesting the unresolved status of Frankfurt's challenges to the standard story of action. Nevertheless, I conclude with an optimistic take on the possibilities offered by causalist approach to agential guidance.

\section{The Breadth and Depth of Frankfurt's Challenge to the Standard Story}

Frankfurt's view on agency is a gradualist picture in which each stage of guidance sophistication is matched with a corresponding level of agency: from a spider's spinning a web all the way to a person's casting a vote. Corresponding to this gradualist picture, Frankfurt proposes two fundamental explanatory challenges associated with the possibility of action and agency: "One is to explain the notion of guided behavior. The other is to specify when the guidance of behavior is attributable to an agent and not simply, as when a person's pupils dilate because the light fades, to some local process going on within the agent's body" (1978, p. 74).

This passage also identifies two different sets of conditions with significant consequences for reductive explanatory strategies like the one championed by the standard story. First, there are conditions related to local agential guidance which can be accounted for by identifying the relevant "local process going on within the agent's body". Second, there are conditions related to global agential guidance in which some such reductive explanatory strategy appears to be insufficient. In this second case we are dealing with the type of guidance involved in intentional actions where the agent participates as a single unified entity and, typically, from a privileged epistemic vantage point.

Frankfurt's main claim is that the standard story fails in explaining both types of agential guidance, and he offers several reasons 
supporting that claim. The first reason is that the standard story is committed to a general causalist view in which something like agential guidance must involve causal regularities of discrete asynchronous events. However, agential guidance involves guiding and guided events that temporally overlap. But, since "an event cannot be guided through the course of its occurrence at a temporal distance" (Frankfurt 1978, p. 72), the standard story is confronted with a significant explanatory challenge.

Causal contemporaneousness is not exclusive of a causalist approach to agential guidance. This is a challenge for any exercise of guidance if it involves guided events taking place at the same time as those that are involved in guiding them. Nevertheless, Frankfurt claims that this challenge is particularly serious in the case of causal theories of action like the standard story. In fact, he claims:

This is what makes causal theories implausible. They direct attention exclusively away from the events whose natures are at issue, and away from the times at which they occur. The result is that it is beyond their scope to stipulate that a person must be in some particular relation to the movements of his body during the period of time in which he is presumed to be performing an action. The only conditions they insist upon as distinctively constitutive of action may cease to obtain, for all the causal accounts demand, at precisely the moment when the agent commences to act. $(1978$, p. 70$)$

Furthermore, such dislocation as to where our attention should be focused is the consequence of embracing a causal picture which also gives rise to what is arguably the most serious challenge to the standard story in the form of causal deviance. Once the gap between the causal antecedents of an action and the event identified with the action becomes possible, all sorts of causally deviant scenarios also become possible. That is, scenarios where the standard story's causal conditions for an event to qualify as an action are satisfied and yet the event is clearly not an action. Presumably, if it were possible to close such a gap, causal deviance would be avoided. ${ }^{4}$ But, according to Frankfurt, such a possibility is unavailable to the standard story:

In my judgment causal theories are unavoidably vulnerable to such counterexamples, because they locate the distinctively essential features

\footnotetext{
${ }^{4}$ Unsurprisingly, this has been a popular suggestion for dealing with causal deviance amongst defenders of the standard story. For instance, see Brand 1984.
} 
of action exclusively in states of affairs which may be past by the time the action is supposed to occur. This makes it impossible for them to give any account whatever of the most salient differentiating characteristic of action: during the time a person is performing an action he is necessarily in touch with the movements of his body in a certain way. (1978, pp. 70-71, my emphasis)

A second significant problem for the standard story, which is explicitly mentioned in this passage, is the need for an agent to be in touch with the guided action. This is a related but different problem from the one corresponding to contemporaneousness insofar as it points to the spatial connectedness which, according to Frankfurt, also links the agent with the guided action. That is, an agent must be literally in touch with her action for as long as such action lasts. ${ }^{5}$ But, given the standard story's way of separating the antecedents of an action from the event that is supposed to be the action, a gap between the two will always be possible allowing for causal deviance, this time exploiting a spatial separation. These two problematic spatiotemporal gaps in the standard story are thus about the agential requirements of causal locality and causal contiguity.

The problems for the standard story arising from the gap between the antecedents of an action and the event that is supposed to be the action have their corresponding epistemic challenge also noted by Frankfurt. Now the causal gap makes it practically impossible to account for the ordinary epistemic direct access that agents have to their ongoing guided action. ${ }^{6}$ Due to the spatiotemporal separation between causes and effects presupposed by the standard story

\footnotetext{
${ }^{5}$ The only significant exception would be cases of ballistic actions which once triggered cannot be directly affected by their agents due to the speed of their execution. The literal understanding of "being in touch" may come as a surprise to some. We can understand this connection in both spatial and/or a temporal way. Frankfurt's contention is that typically when an agent guides an action her connection with it is literally direct or "gapless" in both spatial and temporal ways. This is what distinguishes guiding an action from, say, guiding an object. That is, it always appears to be possible to separate the object under guidance from the guiding agent in both a spatial and/or temporal ways, but, it appears to be impossible to do this with an action under guidance, with the noted exception of ballistic actions. It is the presence of such a gap in the standard story of action which creates several fundamental problems, and, hence, according to Frankfurt, makes it highly counterintuitive. See Kim (2010, pp. 243-262) for a more recent and sympathetic discussion of such literal reading of the "being in touch" type of connection in the case of action.

${ }^{6}$ A classic discussion about the epistemic privileged access that an agent has over her actions is that of Elizabeth Anscombe (1963). There are striking similarities between her views about this aspect of agency and those of Frankfurt's. Her views, as
} 
such knowledge cannot be directly based on what is taking place. Instead, it would have to be based on the outcome of an inference about whether what is taking place matches some antecedent causal condition typically in the form of an intention. The standard story is, in Frankfurt's words, "committed to supposing that a person who knows he is in the midst of performing an action cannot have derived this knowledge from any awareness of what is currently happening, but that he must have derived it instead from his understanding of how what is happening was caused to happen by certain earlier conditions" (1978, pp. 69-70). But this is highly counterintuitive. ${ }^{7}$

The next significant problem for the standard story identified by Frankfurt is particularly evident in the case of global agential guidance. It arises out of the effort to reduce the complex phenomenon of agency to the workings of some parts of the agent. This time the problem is that human agential guidance typically involves the guiding agent as being not just in direct and constant touch with the guided action but wholly so. That is, when agential guidance takes place the agent participates as a single unified entity seamlessly connected with her guided actions. This ordinary exercise of agential guidance is usually distinguished from those cases when guidance is exclusively attributable to one of the agent's parts, say, when an internal mechanism oversees it. Then, it is perfectly possible for the agent to distance herself from such endeavor thereby exhibiting her lack of participation. ${ }^{8}$ Accordingly, unless the whole agent is engaged in the corresponding guidance, her position with respect to the workings of such mechanisms is essentially passive and not agential. Frankfurt famously extends similar considerations to cases where an internal state like a desire fails to be recognized by its agent, for instance, by

opposed to his, have received considerable attention in the rich recent literature on non-observational knowledge of action. The reason seems to be Frankfurt's pointedly metaphysical approach to this issue, particularly as it relates to agential guidance, which - although informed by epistemic considerations - leads in a different direction from the one pursued by those who have followed Anscombe's lead.

${ }^{7}$ Such immediate epistemic access to a corresponding experience of acting is what according to some authors identifies certain events as actions. See C. Ginet 1990 and B. O'Shaughnessy 1973.

${ }^{8}$ All sorts of possibilities emerge out of such distancing. A revealing example is found in several pathologies like the so called "Anarchic Hand" Syndrome, when a proper part of an agent is apparently able to guide complex actions without the agent owning such actions and their consequences. See S. Della Sala et al. 1991, and - for some philosophical discussion of such cases- A. Marcel 2003, and G.W. Humphreys and M.J. Riddoch 2003. 
not being endorsed at some higher hierarchical level in the agent's internal cognitive structure. ${ }^{9}$

Indeed, a problem that is now often considered one of the main challenges to the standard story finds its direct ancestry in Frankfurt's critical remarks about the need to engage the whole agent in agential guidance. A central contention of the standard story is that agential guidance can be reduced to the functional work carried out by some internal processes taking place inside the agent's body, but since an agent is not identical with such processes, the agent herself has been left out of this guidance. As Frankfurt puts it, merely appealing to some "local process going on within the agent's body" is far from engaging the main character of the story, namely, the agent. For evident reasons this type of challenge to the standard story has been called "the Problem of the Absent Agent". ${ }^{10}$

The fact that it is possible to paraphrase the Problem of the Absent Agent in terms of Frankfurt's analysis of agential guidance goes to show the actual breadth and depth of his criticism. Thus, it is rather surprising how little attention this criticism has received, particularly when compared to the sizable attention that other aspects of his views on action and agency usually get. ${ }^{11}$

A possible explanation for this neglect is related not only to the widespread impression that the standard story is well positioned to account for action guidance but that it has in fact already successfully accounted for it at least in general terms. Another possible explanation is a failure to recognize the overall significance of Frankfurt's criticism for the whole explanatory project of the standard story. However, if his way of understanding agency in terms of agential guidance is even partially correct, and if his arguments showing

${ }^{9}$ See Frankfurt 1971 and 1987.

${ }^{10}$ Some early versions of this problem can be found in A.I. Melden 1961 and R. Chisholm 1966; some of its later formulations are offered by D. Velleman 1992 and J. Hornsby 2004. To see how this problem fits in the larger set of challenges faced by the standard story, see J. Aguilar and A. Buckareff 2010. For a detailed causalist reply to this problem see Mele 2003 (pp. 215-233).

${ }^{11}$ One notable exception is Mele's 1997 discussion of Frankfurt's example of guidance in the form of a driver who is coasting without actively intervening in such an apparently guided occurrence. Nevertheless, Mele criticizes Frankfurt's interpretation of this example without exploring further any of the problems associated with agential guidance discussed here. Another notable exception is E. Di Nucci's 2011 analysis of what he considers two different and incompatible notions of action present in Frankfurt's work. Di Nucci identifies one of these two notions as directly informed by Frankfurt's account of guidance, but, again, without examining the challenges related to agential guidance that we are exploring here. 
that this story is incapable of accounting for guidance are sound, it is hard to exaggerate the importance of this criticism for the fate of what these days is essentially the received view about action and agency.

\section{The Standard Story of Guidance}

About the time when Frankfurt criticized the standard story's alleged failure in dealing with action guidance, its supporters were developing richer accounts of agency aimed at explaining the possibility of action guidance by the introduction of mental states like intentions. According to these enriched accounts, explaining action guidance in a causal way is not only possible but is also in a far better explanatory position than a non-causalist approach. The main reason supporting this claim is that for an agent to guide an action there must be some type of mechanism linking the agent and the guided action. In the abscence of a mechanism accounting for guidance, it is completely mysterious how any guiding relationship obtains. ${ }^{12}$

Thus, a defender of the standard story can agree with Frankfurt that agential guidance is a fundamental part of an adequate account of agency, and can take his challenge to be a quest for the causal agential features required for items like intentions to perform such a role. Typically, this challenge takes the form of accounting for what are usually seen as two fundamental features of agential guidance exhibited by both its local and global versions.

The first feature of agential guidance is the agent's capacity to sustain a guided action during the time required for its completion. This capacity can be understood in terms of some motivating force that is present throughout the execution of an action. For just as the initiation of an action requires the exercise of a motivating force, whenever an action takes time to be completed a motivating force has to be exercised throughout the time of its execution, normally until

${ }^{12}$ A conceptual or logical connection can be proposed along the lines of some traditional non-causalist approaches to action and agency. But, besides the wellknown objections to such a view of action and agency, it just seems to be a nonstarter when dealing with something like guidance and monitoring, which are phenomena that exhibit clear empirical and overt aspects. In fact, despite his anti-causalist credentials Frankfurt himself does not seem to be defending a purely conceptual or logical connection between the agent and her guided actions. However, if it is not a causal relationship, it remains obscure what he has in mind as the alternative to the causalist story. As I will emphasize later, Frankfurt's positive story about how the conditions for agential guidance are implemented in the natural world is notably vague. 
its goal is achieved. Furthermore, although during the initial stages in the production of a guided action there is a temporal difference between the guiding antecedents of an action and the action itself, almost immediately, they become contemporaneous and linked by a sustaining causal relationship. It is this sustaining agential capacity that accounts for the ability to interrupt and resume the very same action after some period of inaction.

The second fundamental feature of agential guidance is the agent's capacity to monitor the execution of an action and the relevant conditions surrounding its execution. Without this capacity an agent would be essentially blind with respect to the relevant conditions under which an action takes place. This is the sort of capacity that allows an agent to react adequately during the performance of a guided action by modifying its direction, applying more or less force, or, if needed, to halt its execution altogether. ${ }^{13}$

The sustaining and monitoring aspects of agential guidance significantly raise the bar for the standard story's reductive explanatory approach. This is evident in the traditional move to enrich the features of a single internal state like an intention in order to carry the explanatory weight of action guidance. However, if taken literally, the idea of focusing on a single internal state that could perform the fundamental functions associated with the sustaining and monitoring aspects of guidance is highly implausible. Far more promising is to try to reduce key features of agential guidance to the functioning of some complex agential causal mechanisms which among other things could be seen as informing the agent about the executive status of an action and the relevant conditions during its execution. ${ }^{14}$ Then, internal states like intentions, could plausibly play a central role in agential guidance as items belonging to such functionally complex agential mechanisms.

Although most contemporary versions of the standard story are friendly to the idea that the subject of an action is an agential system,

${ }^{13}$ Ballistic actions are the exception here. For once a ballistic action is triggered, monitoring its execution is essentially inconsequential with respect to its unfolding. Then the agent's relation to such action is essentially passive, letting luck and the world, as it were, do the rest.

${ }^{14}$ Thus, according to a standard story account like M. Brand's, this type of mechanistic approach to guidance leads to the conclusion that "Guidance, apparently, is not a unitary phenomenon; there are a number of mechanisms operative, depending on the degree of automaticity and predictability of future stages. Taken together these mechanisms explain a great deal of the guidance of ongoing activity — though probably not all of it" (1984, p. 181). 
only a handful have tried to articulate this systemic approach to agency. Among them one stands out for its theoretical force and direct relevance for our discussion. This is the systemic causalist model of agency offered by John Bishop. ${ }^{15}$ The main reason for this unique position held by Bishop's model is the centrality that he gives to what is arguably the most fundamental notion related to agency, namely, the notion of agential control. Moreover, keeping in mind that guidance is essentially a type of control, his model is particularly suited to offer an answer to the possibility of agential guidance from the perspective of the standard story. Thus, we can use this model as a paradigmatic representative of the current standard view about the nature of agential guidance and the proposed explanatory strategy to account for it.

Bishop's model of agential control is based on three general causal conditions all directly relevant for agential guidance. First, there is a sensitivity causal condition which requires that whatever qualifies as an action is sensitive to the content of the mental state which causally produced it. Sensitivity here relates to the specific responsiveness that a behavior maintains with the content of the mental state that caused it. If an intention is thought to be the main causal antecedent of an action, then the behavior caused by such an intention must specifically correspond to its content, thereby exhibiting that sensitivity. ${ }^{16}$

The second causal condition captures explicitly one of the two mentioned aspects of agential guidance. This causal condition requires that the relevant antecedent of an action must be capable of exerting its influence during the execution of the action, which often involves several sequential behavioral events. Bishop identifies this capacity as sustained causation. ${ }^{17}$ This second condition is even more fundamental for agential control than the previous one, since "[...] it will be sustained rather than sensitive causation that will form

${ }^{15}$ This systemic account is articulated in Bishop's book Natural Agency (1989) and in several shorter pieces since its publication three decades ago (1997, 2010, 2012).

${ }^{16}$ Bishop's version of the sensitivity condition relies on the work of C. Peacock 1979, D. Lewis 1980 and M. Davies 1983.

${ }^{17}$ In introducing this condition as a type of causation Bishop is careful to keep his traditional causalist credentials by reminding us that "Sustained causation [...] need not be some mysterious special form of causation, whose place in the natural order might be suspect. The sustained causation of a particular outcome [...] may be achieved by quite a straightforward event-causal mechanism." (1989, p. 169) 
the nub of agent-control" (1989, p. 171). ${ }^{18}$ Once more the sustaining side of agential control is carried out by an intention functionally understood in mechanistic terms:

For an intention to be the sustaining cause of a behavioral sequence is just for it to feature appropriately in a causal mechanism that counts as a servosystem having the production of the intended behavior as its function. This suggested identification [... is the idea] that once the agent forms a basic intention, his or her motor system realizes a transient servosystem whose function is to produce or maintain the intended behavioral sequence. $\left(1989\right.$, p. 169) ${ }^{19}$

Bishop's third causal condition related to agential control —and typical of all systemic standard story accounts - is a feedback causal condition exhibited by the operation of the controlling servosystem which accounts for the monitoring and modification of ongoing actions. The feedback condition is once again satisfied by the functioning of an intention belonging to the appropriate servosystem.

Besides these three causal conditions involved in agential control, Bishop's model places the relevant intentions inside a complex network of causal relationships which engage other agential mechanisms. First, such intentions are directly responsive to other cognitive mechanisms involved in intention formation and practical reasoning;

${ }^{18}$ The inclusion of a sustaining aspect in the production of an action goes back at least to I. Thalberg 1984 who in turn was inspired precisely by Frankfurt 1978. Moreover, the literature on intentions often captures some features of such a sustaining aspect. For example, J. Searle (1983) proposed the need for a unique type of intention explicitly relevant for those actions that require an ongoing sustaining support in the form of an intention-in-action. See also B. O'Shaughnessy 1991, J. McDowell 2011, and E. Pacherie 2000. There is also a traditional way of distinguishing intentions whose agential impact is immediate from those intentions which exert their influence over time. This widespread distinction is motivated by the need to characterize intentions in terms of their temporal scope, and, hence, the ability to sustain their influence over time. See J. Searle 1983, M. Bratman 1987, and A. Mele 1992.

${ }^{19}$ This is how Bishop characterizes the nature of such servosystems and their fundamental role as causal sources of control: "We know that many natural systems (both designed and evolved) count as control systems. In the very broadest sense, any system whose output is a mathematical function of its input might be described as 'controlling' its output. Usually, however, a system requires a greater complexity of function before we think of it as maintaining control. Systems that incorporate negative feedback mechanisms provide the standard example - they maintain control by keeping their output within a restricted range despite a contrary tendency. In cybernetics, these mechanisms are known as servosystems: They produce or maintain a given output by means of feedback loops" (1989, p. 168). 
second, they are functionally linked to the cognitive mechanisms processing the information required for the monitoring and modification of ongoing behavior; and third, the relevant intentions engage what Bishop calls "central mental processes" or "central processes of the agent's brain". ${ }^{20}$

If we bring together the different elements making up Bishop's systemic account of agential control as it bears on the possibility of guidance through sensitivity, sustaining, and feedback causation, together with the work of guiding intentions, a rather complex picture of systemic agency emerges that seems to cope rather well with some of the features of agential guidance stressed by Frankfurt. That is, we can see how Bishop's model offers an agential control system that accounts for guided actions by making use of contemporaneous sustaining feedback loops ultimately controlled by the central processes of the agent's brain, themselves functionally connected to several cognitive mechanisms associated with intention formation, practical reasoning, and behavioral monitoring. In particular, Bishop's systemic approach to agency seems to account for the possibility that a single type of internal state like an intention could play the main guiding role as long as it is understood as belonging to mechanisms nested inside the complex agential machinery. This suggestion relieves intentions from an otherwise counterintuitive onerous functional role typical of non-systemic versions of the standard story.

\section{The Limits of the Standard Story of Guidance}

We have seen how, through a combination of an enriched notion of intentions and their placement within agential systems exercising control over actions, the supporters of the standard story seem to have a plausible way to account for agential guidance. Nevertheless, I am now going to argue that, as it stands, and despite its initial plausibility, the dominant causalist model of agential guidance exhibits significant shortcomings when dealing with the challenges identified by Frankfurt. In this last section I am going to emphasize two general issues that are particularly challenging: first, the difficulty in locating the actual sources of action guidance, which are typically identified

${ }^{20}$ Although Bishop does not analyze the nature of these central processes, they seem to be the agential control center to which the feedback information arising from the execution of an action goes and from which the corresponding agential directives come, presumably in a way that is consciously accessible to the agent. Their appearance in Bishop's model of agential control takes place during his effort to deal with particularly hard cases of basic causal deviance involving two agents which he identifies as "heteromesial" (1989, p. 125). 
with the causal role given to guiding intentions; second, the limitations that a content-based strategy exhibits in accounting for the correct identification of an action under guidance. I will illustrate these challenges using again Bishop's causalist model, as this will show how one of the most sophisticated available standard systemic approaches to agency exhibits such deficiencies.

Although Bishop's account of the controlling role of intentions incorporates them as part of some mechanisms which, strictly speaking, are the sources of control and guidance, these mental states continue to play the central role in his standard story of agential control. More specifically, we are told that intentions can perform such roles insofar as they "feature appropriately" in the corresponding functional servo-system mechanism, a suggestion which initially appears plausible. That is, until we focus our attention on the specific relationships that intentions need to have with the relevant agential mechanisms involved in guidance, particularly their relationship with the central mental processes that Bishop posits as critical for agential control. Then, the shortcomings arising from the sketchiness of this model become evident. In fact, then, it is not altogether clear what item in the model is performing the required guidance.

Consider a basic question. Anytime that a feedback mechanism is invoked to account for any type of control, there must be something on the receiving end of such a mechanism which oversees the incoming information. However, in cases involving sustained causation, to use Bishop's terminology, if we try to figure out what item in the model is being fed with the relevant information coming from the execution of an action, it is unclear what the answer to this basic question is. As suggested earlier, this item cannot plausibly be identified with a single mental state like an intention. For no matter how much a single mental state is enriched with attributes, it is highly implausible that it could be capable of processing information, modifying it accordingly, and sending it back to the corresponding action. So, if an intention as traditionally conceived is not capable of playing such a guiding role, then a pressing question for Bishop's model is to identify what exactly is playing this key role. There are only few alternatives available to answer this question.

One answer is to take some of the claims made by Bishop at face value and, at least for the case of motor behavior, identify the relevant guiding intention with some "transient" servosystem. This proposal seems to be the one embraced by Bishop when he explicitly talks about the sustaining causes of intentional bodily movements: 
[...] the idea is that once the agent forms a basic intention, his or her motor system realizes a transient servosystem whose function is to produce or maintain the intended behavioral sequence. An agent's motor system will then be flexible enough to form, as occasion demands, servosystems subserving each of the basic action types in his or her repertoire. The concept of servosystem is thus being employed here simply to defuse the ontological oddity of unexplicated sustained causation (1989, p. 169).

Bishop is aware of the pressure arising from potential criticisms which will emphasize the "ontological oddity" of introducing a single mental state as capable of causally sustaining intended behavioral sequences together with the presence of a unique type of causation that would account for this capacity. So, at least in this passage, his systemic solution is to functionally identify a guiding intention with a transient mechanism. ${ }^{21}$

This type of identification only pushes the question one step further, since now we wonder which part of the servosystem is doing the complex job of processing the relevant information and how exactly we should understand such a process. We need to explain how a single and unspecified part of a servosystem can oversee the receiving, processing, and sending back of information for the servosystem to continue operating. Furthermore, a looming problematic regress is evident in this type of proposal. For breaking the servosystem into receiving and executive parts immediately raises the same problems that we are trying to answer, this time with respect to its receiving part.

This explanatory shortcoming leaves a second option as the more plausible one, namely, the possibility that some central mental items oversee the information coming from the appropriate feedback mechanisms. There is support for this alternative in Bishop's presentation of his model of agential control. As we saw earlier, central mental processes are introduced as elements in the receiving end of the feedback information involved in what amounts to the agent's general exercise of control. ${ }^{22}$ However, the basic problem with this proposal is Bishop's notable vagueness in characterizing these central mental

${ }^{21}$ The idea of identifying an intention with a mechanism's main function is a natural move in a systemic agential causalist approach to guidance. This move is particularly fitting in cases related to local guidance. Some recent suggestive empirical models of action guidance explore such an approach; see for instance Mylopoulos and Pacherie 2017, and Shepherd 2017, 2018.

${ }^{22}$ This type of suggestion is offered by Bishop to deal with cases related to potential scenarios involving causal deviance where the real sources of agential control are 
processes. Nowhere does his, or for that matter any other similar systemic reductive approach associated with the standard story, fully unpack the functioning of these kinds of central mental processes which carry so much explanatory weight. Not surprisingly, all sorts of unanswered questions concerning them inevitably arise. For instance: how are these processes supposed to play the monitoring role to make sure the action and the relevant surrounding conditions match the intended goal and action plan? By "central" should we understand some type of sophisticated meta-cognitive processing center consciously accessible to the agent? And so on.

Moreover, let us note that favoring the move in the direction of some central processes as sources of agential control diminishes significantly the reductive strategy of accounting for guidance by appealing to parts of the system that would carry out such a task, which in the case of Bishop's model involves transient servosystems. Not only would a guiding servosystem require an internal structure, with one of its component parts in charge of receiving, processing, and sending back the relevant information, suggesting an explanatory regress, but in the case of most guided actions, such a presumably non-autonomous transient servosystem would have to be in turn guided by the agent, thus defeating the servosystem's alleged controlling capacity.

The move to account for core agential capacities by appealing to some central mental processes immediately recalls something that Bishop himself would recognize as the specter of agent causation. That is, the presence of some unique type of central control mechanism which carries out the distinctive causal contribution of the agent in a way that resists further analysis in more basic terms. There is something ironic about raising this worry about Bishop's model since arguably his long-term theoretical project has been an effort to exorcize the specter of agent causation by means of a reductive account of agency. Nevertheless, until a corresponding reductive account of those central mental processes is offered, or at least some analysis is provided that sheds light on their nature, this type of centralized agential model seems to end up appealing to the theoretical equivalent of an unanalyzable substantial entity located at the end of the process of agential control.

unclear. Hence, the sensitivity condition appears to be insufficient to guarantee true agential control: "It seems, then, that to analyze the notion of sustained causation by a basic intention, we need to require of the transient servosystem realizing this function that it be engineered in such a way that it is the agent's own central mental processes that register and respond to feedback information" (1989, p. 170). 
Here it would be tempting to suggest that, even if correct, this criticism only shows that further empirical work is needed to answer it. There is clearly something to be said in favor of this suggestion, considering how much these types of systemic agential models rely on the empirical work on guidance, particularly on the more circumscribed efforts to make sense of the mechanisms involved in guiding bodily movements. Bishop's use of the notion of servosystem being a case in point. However, valuable as such empirical research is, it would be a mistake to suggest that it can be a substitute for the conceptual modeling work that we are exploring here. In fact, it is only when this type of conceptual model is in place that much of the empirical inquiry associated with its evidential corroboration or lack thereof begins. Furthermore, given the foundational character of several of the key notions at stake, such as those of agency and guidance, such a suggestion misses the mark of the sort of task at hand which to a great extent involves the identification of those properties that characterize these basic notions. ${ }^{23}$

There is a second significant source of difficulties for the standard story related to guidance. Just as whatever is exercising action guidance must preserve its identity throughout the execution of the action, say, be the same sustaining intention, on the opposite side of the controlling relationship the same action must be under the guidance of its agent. In the case of a feedback agential system, the very same action must be continuously related to its guiding agent through a feedback causal loop. The very same action must be causally connected to its causal source, produce the intended consequences for which it was brought forth, and maintain informed whatever functions as the guiding control center about its ongoing status. The challenge is to specify with some minimal precision which of the events belonging to a complex agential network qualify as the action under guidance.

Typically, for a defender of the standard story the identification of an action with an event like a bodily movement is somewhat straightforward. The identification takes place in the form of some specific correspondence between the content of the mental item that is causing the action and the event that corresponds to the action. In these cases the identity of an action will depend directly on the specific content of such an antecedent mental item. However, in the

\footnotetext{
${ }^{23}$ Bishop himself rejects a similar proposal related to an answer to the problem of causal deviance which authors like Alvin Goldman suggested as being ultimately an empirical issue to be settled by scientific modeling and research.
} 
dynamic and complex causal context of guidance this simple strategy is problematic.

If the content of an antecedent mental item is going to play the role of identifying which event or sequence of events is the guided action, such representational content has to be flexible enough to allow for a whole array of potential event modifications that would qualify as belonging to the same action. The only way in which this flexibility can be accounted for is by the absence of content specificity. But then the idea that the corresponding content will serve as the source of identification for an action under guidance loses its force. Now all we have in the form of a guiding content is some sketchy action type linked to some general goal. That is, an action type that is vague and flexible enough to accommodate the necessary adjustments in the actual guiding performance. The problem with this loosening of the relevant guiding content is that most guided actions are very specific and fine-tuned to accomplish their goal. And, yet, if the corresponding guiding content is narrowed down by making it very specific in the form of an equally specific action type, then the modifications and adjustments that take place in guided actions would not be accounted for. Again, the identification of the relevant action is lost. It appears then that in the case of agential guidance both strategies to adjust the relevant content to the requirements of action identification run into a dead end.

What may seem to be a metaphysical complication for standard systemic models of agency bears directly on the way in which such models are supposed to capture the relevant mechanisms involved in action guidance, particularly those involved in the formation of intentional repertoires containing the available types of actions that an agent may intend to perform. Generating such intentional repertoires presupposes some way of distinguishing the different types of actions in the form of some corresponding behavioral correlates. The problem with the dynamic and yet exact nature of guided actions is that the corresponding behavioral correlates are very hard to pin down for the reasons mentioned above. Therefore, this problem makes the very formation of the relevant action-types that make up the intentional repertoire of an agent a mystery, and, a fortiori, their use in providing guiding intentions with their relevant content.

Here is Bishop, making use of such action-types, in his analysis of transient servosystems quoted earlier: "An agent's motor system will then be flexible enough to form, as occasion demands, servosystems subserving each of the basic action types in his or her repertoire." 
Unfortunately, nothing in his model addresses the worry as to how such basic action types in the repertoires of agents are formed, and, more to the point, how they would respond to the specific demands imposed by a dynamic content involved in action guidance. Bishop's sensitivity condition is simply silent with respect to the specific way in which the corresponding guided action needs to reflect the appropriate content of the antecedent intention that is guiding it. Consequently, the very thing that needs to be identified as under control becomes elusive, to put it mildly.

If this criticism is correct, we find ourselves facing another significant challenge to the systemic standard story of guided agency. In the same way that the standard story - as is often suggestedmakes it difficult to recognize the agent when all it offers are internal events causing actions, in this feedback model the actions themselves are now very hard to spot when applied to action guidance. ${ }^{24}$

\section{Conclusion}

If one embraces the idea that agency boils down to the capacity to produce an action, one will be tempted to think that once one has a causal account of the antecedents of an action one also has an account of agency. This has been the implicit and reasonable assumption behind the standard story, which was thereby traditionally seen by many as encompassing a corresponding causalist account of agency. However, during the most recent decades of philosophical theorizing about action and agency there has been a steady moving away from this theoretical identification. The work of Frankfurt has motivated such a division of labor by advancing a richer and more nuanced account of agency without necessarily doing as much with respect to the nature of action. Whether or not one agrees with his general understanding of agency as essentially a type of guidance, his story of agency is not simply a story of action. For even if one has exhausted the conditions that generate an action one would still have to address the question of how an entity can exhibit them. Merely talking about the capacity to produce an action leaves untouched the question as to what it takes to possess and exercise this capacity.

But then we must concede that the best chance that the standard story had to cope - not only with the localized worry about action

${ }^{24}$ Elisabeth Pacherie suggests the need for what she calls content "dynamical indexicality" (2000, p. 414) to try to cope with this challenge. Nevertheless, this remains a rather schematic proposal in need of further development. See also Shepherd 2018, 2019. 
guidance suggested by Frankfurt but also with his more general interpretation in which it becomes synonymous with agency - is in trouble. This is bad news for the standard view. If a sophisticated systemic agential model like Bishop's cannot explain it, it is unclear what version of the causalist story would. ${ }^{25}$ However, it is possible to remain cautiously optimistic that some causalist standard account of agential guidance, and ultimately of agency in general, will ultimately address the worries explored in this essay.

Frankfurt is evidently not alone in rejecting the causalist approach to action and agency. Nevertheless, it is safe to say that, for all its critical merits, his and all the anti-causalist approaches to agential guidance are in worse shape than their causalist counterparts. Much as his criticism generates genuine questions about the causalist account of agential guidance, the reluctance to embrace things like causal mechanisms makes it utterly mysterious how any type of guidance is possible in a physical world in which things like guided intentional bodily movements take place. Likewise, the opposition to identify items such as intentions as directly relevant to agency and guidance seems equally misguided. We simply do not have a competing alternative to the fundamental explanatory role played by internal states such as intentions. Surely, in our agential models we

${ }^{25}$ Here one may wonder if there are alternative systemic approaches to agential guidance that following roughly the standard story's reductive approach nevertheless could perhaps account for such guidance without having to appeal to either some key guiding items like intentions or some central executive function performed as Bishop suggests by some central processes of the agent's brain. Perhaps by distributing the agential guiding load into several other components of the agential system one might account for such guidance without running into the mentioned problems for Bishop's account. However, this type of distributed systemic agential guidance is not open to Bishop's model given the emphasis that he places on both the guiding intentions and the central higher level processes, something that ultimately creates not only an explanatory tension in his account but the serious individual shortcomings we just explored. Furthermore, distributing agential guidance forces us to confront the inevitable issue of the locus of agential control, particularly when accounting for things like the monitoring and sustaining of an action under guidance. For all its limitations, Bishop's account identifies such a locus of agency with the agent's higher functions. For him this is ultimately the source of agential moral responsibility which is the main explanatory goal of an account of natural agency like his. But, even if one does not share such a lofty goal in framing the problem of agential guidance as ultimately one about the possibility of moral responsibility in a natural world, it is simply unclear how a distributed account of agential guidance could deliver the required elements to make sense of the mentioned phenomena. Not surprisingly this proposal has not been explored within the standard story approach, although it is as suggestive idea. I want to thank an anonymous referee for raising this point. 
want to engage the agent in guiding her actions in a continuous, direct, and epistemically privileged manner, but this must be done in a way that is metaphysically unexceptional and amenable to a naturalistic picture of agency. This continues to be the promise and appeal of some as yet fully unrealized causalist standard story of agential guidance. ${ }^{26}$

\section{REFERENCES}

Adams, F. and A. Mele, 1989, "The Role of Intention in Intentional Action", Canadian Journal of Philosophy, vol. 19, no. 4, pp. 511-531.

Aguilar, J. and A. Buckareff (eds.), 2010, Causing Human Actions: New Perspectives on the Causal Theory of Action, The MIT Press, Cambridge, Mass.

Anscombe, G.E.M, 1963, Intention, 2nd ed., Cambridge University Press, Cambridge.

Bishop, J., 2012, "Exercising Control in Practical Reasoning: Problems for Naturalism about Agency", Philosophical Issues, vol. 22, pp. 53-72.

— 2010, "Scepticism about Natural Agency and the Causal Theory of Action", in J. Aguilar and A. Buckareff (eds.), Causing Human Actions:

New Perspectives on the Causal Theory of Action, The MIT Press, Cambridge, Mass., pp. 69-83.

—_, 1997, "Naturalising Mental Action", in G. Holmstrom-Hintikka and R. Tuomela (eds.), Contemporary Action Theory, Volume 1: Individual Action, Kluwer, Dordrecht, pp. 251-266.

- 1989, Natural Agency: An Essay on the Causal Theory of Action, Cambridge University Press, Cambridge.

Brand, M., 1984, Intending and Acting: Toward a Naturalized Action Theory, The MIT Press, Cambridge, Mass.

Bratman, M., 1987, Intentions, Plans, and Practical Reason, Cambridge

University Press, Cambridge, Mass.

Chisholm, R., 1966, "Freedom and Action", in K. Leher (ed.), Freedom and Determinism, Random House, New York, pp. 11-44.

Davies, M., 1983, "Function in Perception", Australasian Journal of Philosophy, vol. 60, no. 4, pp. 158-162.

Della Sala, S., C. Marchetti, and H. Spinnler, 1991, "Right-Sided Anarchic (Alien) Hand: a Longitudinal Study", Neuropsychologia, vol. 29, no. 11, pp. 1113-1127.

${ }^{26}$ This paper is the result of my work with Andrei Buckareff on several issues related to the nature of agency. As always, I am deeply grateful for his help and support. I want to thank Randy Clarke for detailed comments to an earlier version presented at the AAMP 2019 Conference in Florida State University and to its audience. Thanks also to several anonymous referees. 
Di Nucci, E., 2011, "Frankfurt versus Frankfurt: a New Anti-Causalist Dawn", Philosophical Explorations, vol. 14, no. 1, pp. 117-131.

Enç, B., 2003, How We Act: Causes, Reasons, and Intentions, Oxford University Press, Oxford.

Frankfurt, H., 1987, “Identification and Wholeheartedness", in F.D. Schoeman (ed.) Responsibility, Character, and the Emotions: New Essays in Moral Psychology, Cambridge University Press, Cambridge, pp. 27-45.

—_, 1978, "The Problem of Action", American Philosophical Quarterly, vol. 15, no. 2, pp. 157-162.

- 1971, "Freedom of the Will and the Concept of a Person", Journal of Philosophy, vol. 68, pp. 5-20.

Ginet, C., 1990, On Action, Cambridge University Press, Cambridge.

Hornsby, J., 2004, "Agency and Actions", in J. Hyman and H. Steward (eds.), Agency and Action, Cambridge University Press, Cambridge, pp. 1-24.

Humphreys, G.W. and M.J. Riddoch, 2003, "Fractionating the Intentional Control of Behaviour: A Neuropsychological Analysis", in J. Roessler and N. Eilan (eds.), Agency and Self-Awareness, Oxford University Press, Oxford, pp. 201-217.

Jeannerod, M., 2006, Motor Cognition, Oxford University Press, Oxford. - 1997, The Cognitive Neuroscience of Action, Blackwell, Oxford.

Kim, J., 2010, Essays in the Metaphysics of Mind, Oxford University Press, Oxford.

Lewis, D., 1980, "Veridical Hallucination and Prosthetic Vision", Australasian Journal of Philosophy, vol. 58, no. 3, pp. 239-249.

Marcel, A., 2003, "The Sense of Agency: Awareness and Ownership of Action", in J. Roessler and N. Eilan (eds.), Agency and Self-Awareness, Oxford University Press, Oxford, pp. 48-93.

McDowell, J., 2011, "Some Remarks on Intention in Action", The Amherst Lecture in Philosophy, vol. 6, pp. 1-18.

Melden, A.I., 1961, Free Action, Routledge and Kegan Paul, London.

Mele, A., 2003, Motivation and Agency, Oxford University Press, Oxford. , 1997, The Philosophy of Action, Oxford University Press, Oxford.

- 1992, The Springs of Action, Oxford University Press, New York.

Mylopoulos, M. and E. Pacherie, 2019, "Intentions: The Dynamic Hierarchical Model Revisited", WIREs Cognitive Science, vol. 10, no. 2, el481. , 2017, "Intentions and Motor Representations: The Interface Challenge", Review of Philosophy and Psychology, vol. 8, no. 2, pp. 317336.

O'Shaughnessy, B., 1991, "Searle's Theory of Action", in E. Lepore and R. Van Gulick (eds.), John Searle and His Critics, Blackwell, Oxford, pp. 271-288.

- 1973 , "Trying (As the Mental "Pineal Gland')", The Journal of Philosophy, vol. 70, no. 13, pp. 365-386. 
Pacherie, E., 2011, "Non-Conceptual Representation for Action and the Limits of Intentional Control", Social Psychology, vol. 42, no. 1, pp. 6773.

— 2008, "The Phenomenology of Action: A Conceptual Framework", Cognition, vol. 107, no. 1, pp. 179-217.

_ 2 2000, "The Content of Intentions", Mind and Language, vol. 15, no. 4, pp. 400-432.

Peacock, C., 1979, "Deviant Causal Chains", Midwest Studies in Philosophy, vol. 4, no. 1, pp. 123-155.

Searle, J., 1983, Intentionality, Cambridge University Press, Cambridge.

Shepherd, J., 2019, "Skilled Action and the Double Life of Intention", Philosophy and Phenomenological Research, vol. 98, no. 2, pp. 286305.

— , 2018, "Intelligent Action Guidance and the Use of Mixed Representational Formats", Synthese. (doi.org/10.1007/s11229-018-1892-7).

— 2017, "The Experience of Acting and the Structure of Consciousness", Journal of Philosophy, vol. 114, no. 8, pp. 422-448.

Smith, M., 2012, "Four Objections to the Standard Story of Action (and Four Replies)", Philosophical Issues, vol. 22, pp. 387-401.

Thalberg, I., 1984, "Do Our Intentions Cause Our Intentional Actions?", American Philosophical Quarterly, vol. 21, no. 3, pp. 249-260.

Velleman, J.D., 1992, "What Happens When Someone Acts?", Mind, vol. 101, no. 403, pp. 461-481.

Received: June 29, 2020; revised: August 12, 2020; accepted: August 17, 2020. 